Technical Reports

\title{
Electric, Solar and Fuel Car Convertible Boat, Vertical Aircraft Flying Supersonic
}

\author{
${ }_{1,2,3,4}$ Seyed Ali Akbar Mousavi \\ ${ }^{I}$ IRAN - FARS - MAMASANI - Azad University of NORABAD, \\ ${ }^{2}$ Membership in WIPO, PCT, ICRC, ISI, \\ ${ }^{3}$ Membership in IRANIAN INVENTORS ASSOCIATION - inventors, \\ ${ }^{4}$ IRAN - FARS - Mamasani - Totestan - Alley Qhodosi 22, My Lab and My Workroom
}

Article history

Received: 21-03-2020

Revised: 07-09-2020

Accepted: 09-09-2020

Email: invention500@gmail.com invention550@gmail.com
Abstract: In this project I intend to discuss the technology design project that we can speed up relief and aid to those affected by the accident or military, security and political affairs and I've designed a project that electric car and jet fuel with highly capability is able to convert to a boat, vertical aircraft fly and supersonic and has been compared to other vehicles.

Keywords: (1) Electric and solar and all fuel, (2) Anti-crash. Anti-accident in speed $40 \mathrm{~km}$ limit. (3) 9 Convertible Status: Boat, car 1, 2, 3 and 4, vertical fly aircraft, near-sound aircraft, ultrasonic aircraft and very fast ultrasonic aircraft. (4) Induction brake with clutch motor and brake with compressed air and brakes with aerodynamic vehicle mode and brakes using jet engine exhaust and brake with jet engine shaft and brakes with gearbox and brakes with 2 discs. (5) Stability of Control System brake and Stability with exhaust system and Stability of car with shock absorber system. (6) Brakes with negative acceleration about $1-2 \mathrm{sec}$ from $100 \mathrm{~km}$ to zero. (7) Acceleration controllable 1 to $2 \mathrm{sec}$ from zero to $100 \mathrm{~km} / \mathrm{h}$. (8) Excellent efficiency in jet engine, clutch, gearbox, exhaust and power transmission system with shock absorber and solar battery energy. (9) Has a parachute with controllability

\section{Introduction}

In this world, many vehicles are designed and built in technology that each has its own place but when we speak of time in events are (Judicial Services, the human rights services of United Nation, ambulances or natural disasters and accidents) transfer from one vehicle to another vehicle takes a lot of time and there are risks because when we go from place to expected place, the time is finished and/or criminal disappears.

In this project I intend to discuss the technology design project that we can Speed up relief and aid to those affected by the accident or military, security and political affairs and I've designed a project that electric car and jet fuel with highly capability is able to become a boat, vertical aircraft fly and supersonic and has been compared to other vehicles.

\section{Materials and Methods}

In this project, I designed and tested about 3 inventions and 5 initiatives and I failed and I could not design it but I have designed and tested about more than 24 inventions and 12 new initiatives and 200 new industrial designs in this project and I succeeded.
I will send all other articles about this vehicle in the future.

I will send all articles and inventions of this vehicle in the future, till be registered.

This vehicle includes 9 generations.

Specifications of this vehicle:

\section{Design}

I have designed the car in somehow that each piece does about 5 common and independent work with other pieces such as electric motor, generator, part of brake, clutch, gearbox and etc. for this reason it has weighs half a similar plane. Can be done by one piece, so there are no failures in the mission.

\section{Convertible Status}

Pic

Boat, car 1, 2, 3 and 4, vertical aircraft, near-sound aircraft.

\section{Engines}

In car mood, 2 jet engines independently, transfer their force in turbo shaft mood through gearbox to force 
conduction system and to front/back wheel that it can to work with fuel or hybrid and/or only with electric motor and/or only with tail jet engine move to method turbo.

This car has ability to move to back too.

\section{Anti-Enter Bird to System of Motor}

It is a system if the bird is felt before entering the engine a window and windows open and/or the compressor window closes and the engine convert into rocket mode with low latency and the bird is not allowed to enter the engine.

\section{High-Advance Gearbox of My Design}

Primary technology design two gearbox with electric motor and clutch and two of brakes applying to wheels fixes on this system and I design it on paper that it has 48 shifting gears move to front and 48 Shifting gears move to back and the number of gear wheel are about 34 that two numbers operate the working for front and back and two other numbers operate work for shifting gears change that it connect to many circuits and central computer and sensors.

Repair and change of more components and ball bearings of this gearbox is an easy job and motor force perfect and protracted with shifting gears without delay is transferred to wheels (I want to break world record with delay 8 milliseconds advance cars gearbox with this gearbox).

This car is a mountain car too, so it needs to gearbox with little rotation and powerful and this car can to convert to plane so in high speed about $300 \mathrm{~km} / \mathrm{h}$ it needs to high speed of gearbox.

So making a gearbox with 48 is necessary. In this 48 shifting gears, motor rotation when shifting gears has intangible alteration (It does not feel).

Making of this gearbox does not exist lesser than 12 shifting gears change and with this 12 shifting gears is in need of change with time delay with use of clutch and it has little mass difference and I selected model shifting gears 48 .

In this system, it needs 3 statuses for clobber change on the gearbox:

1- Previous shifting gear

2- Force conduction with status shifting gear to negative acceleration and positive acceleration

3- Next shifting gear

4- Disable state 2

All is operated via central computer and electronic circuit.

\section{Clutch and Electric Motor and Brake and Generator and Starter in One Component}

In this system for jet engine there are clutch 2 till for jet engine back and front components not be destroyed:

1- The clutch optimal of start move moment with conduction of 0 to $90 \%$ with a performance delay of 3 microseconds and all jet engine force with a performance delay of 1 seconds

2- The clutch of perfect force of engine after the beginning of motion: All these components (clutch and electric motor and brake and generator and starter 1) inserts in a small component with mass $20 \mathrm{~kg}$ that I designed it 12 years ago on paper and I succeeded and I made it in small dimensions and now I have begun design in SolidWorks software (Fig. 1)

3- There is no abrasion in this clutch because it works by magnetic induction and it doesn't need a power supply. The inductive efficiency of this clutch is about 90\% (According to the law of magnetic induction) and it can transmit all the power of the engine

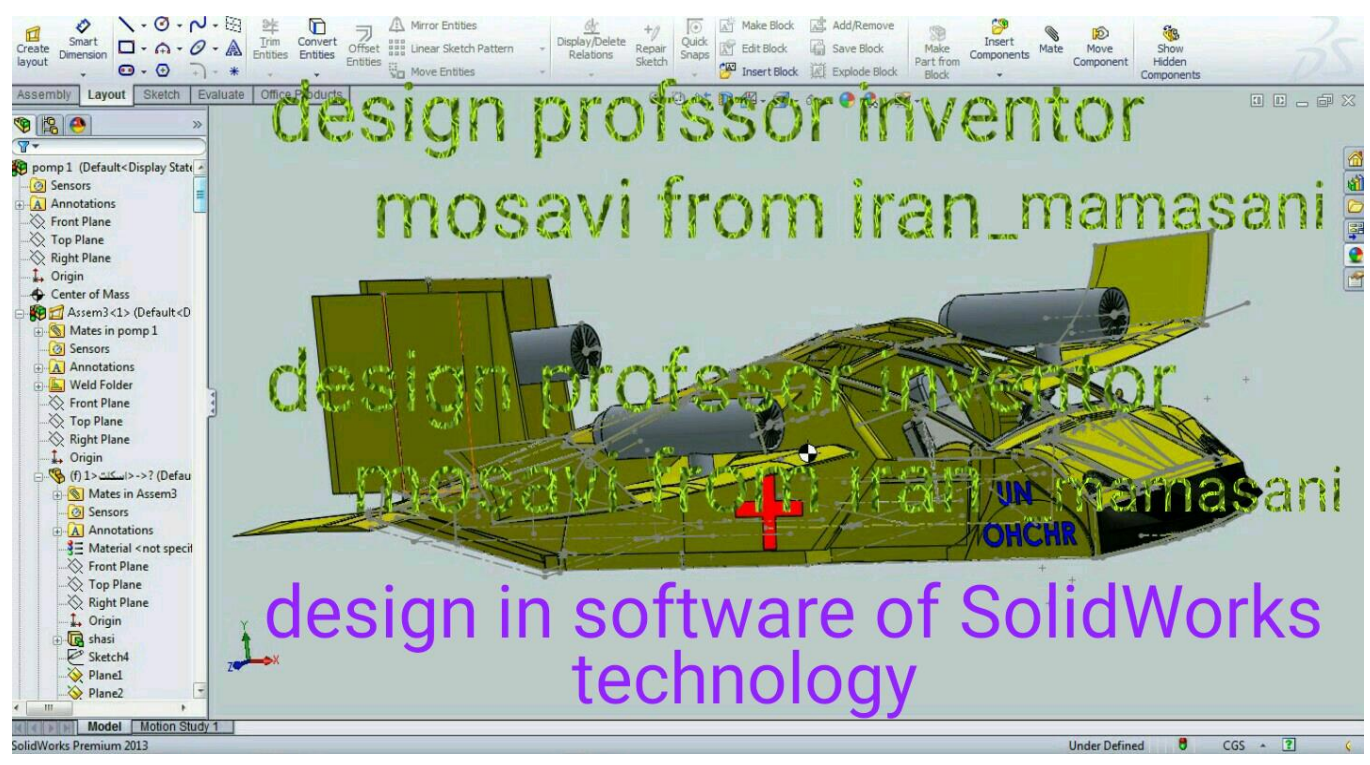

Fig. 1: Design SolidWorks 
The number of test and design photos is a lot. I just put a few.

\section{Material Scientific}

Use of Aluminum for making first project. In second project use of Aluminum and carbon composite for selling to international bazaar and high advance project anti-accident suitable for international markets.

\section{Starter}

It has three Common starters, that it does the work of 8 starter varieties of vehicle and is very advanced.

\section{Jet Motors}

It has 9 motors in configuration $3 \times 3$.

\section{Electric Propulsion Motor}

2 Electric motor independently and hybrid with jet engine, apply force to tires.

Mass

Approximate mass about 1700 to $2300 \mathrm{~kg}$.

\section{Battery (Solar and Heat)}

Solar battery rests on waistline and other in vehicle and battery heat (heat convert to electric) on jet engine.

\section{Acceleration}

Acceleration is less than $2 \mathrm{sec}$ in $100 \mathrm{~km}$ that applied to tires and air with helping jet engine and electric motor.

Brake

Brakes with negative acceleration about 1-2 sec from $100 \mathrm{~km}$ to zero.

\section{Steering Control}

It has two steering rudder and a steering wheel and a mechanical steering and it has capability control all direction this vehicle and I designed steering of 9 vehicles in this Steering control and it is a little similar to steering car formula 1 (Fig. 7).

When steering is in your arm is like that flying boat car in your arm that I designed this technology on paper and technology design is finishing on SolidWorks software.

This steering send data with 4 method electronic and digital and wireless to central multiple electronic system and central computer.

In this steering all buttons of control have been designed and it has 2 Touch screen that method selection displayed a section of specifications (engines and electric motors and vehicle and other screen is in steering and with pressing a button, it is ejected and GPS, camera and some specifications are showed.

I can design and program the technology of all electronic circuits. A steering wheel other reserved mechanical has been designed on paper.

\section{Waterproof}

It is waterproof even in section of front too, that with use of valves these parts with a motor with other usage is closed and waterproofed spontaneously and also there is an air pump that air pressure prevents of entry water to fender.

\section{Chair}

Chair is of air and it can convert to bedstead and/or stretcher for the sick.

\section{Auto Drive}

This vehicle has Autopilot and auto chauffeur that I have done artificial intelligence programing and for cameras, sensors, main communication and motors.

\section{Anti-Crash Operation Levels}

This vehicle guarantees several levels anti-crash operation of 3 level to 6 level for arriving to destination and if after 6 levels with possibility about 0.00001 , systems and all levels do not answer or be destroyed, the only way is the use of aerodynamics brakes and rocket motor and brake and parachute (Fig. 5).

\section{Landing and Take-Off}

This vehicle (my project) can land and take-off on road, street, river and sea, on slope 60 degrees such as mountain or e other places and landing or take-of.

\section{Type of Fuel}

Ability of use of widespread varieties of liquid fuels and gas (polar, nonpolar) with various octane number and it can use several solid fuels too such as alcohol, nitro, oil, gas oil, gas, $\mathrm{CNG}$, wood and etc.

This style is possible with usage of new technology consumption fuel with intelligent control without creation of smoke and soot in this system that I designed, invention and tested.

\section{Differential}

The differential is the same car's simple differential that has a number for the front tires and a number for the rear tires.

\section{Doors Vehicle}

Doors of this vehicle have been deleted and $50 \%$ of static stability of this vehicle has been increased and doors design into front.

\section{Suspension Specification and Axle Back}

In this suspension I have designed a new mechanism that is of Carbon fiber or steel alloy and it can close the fender with a valve and is waterproof and it can lift up chassis to one meter of ground and it is connected to very powerful shock absorber. 


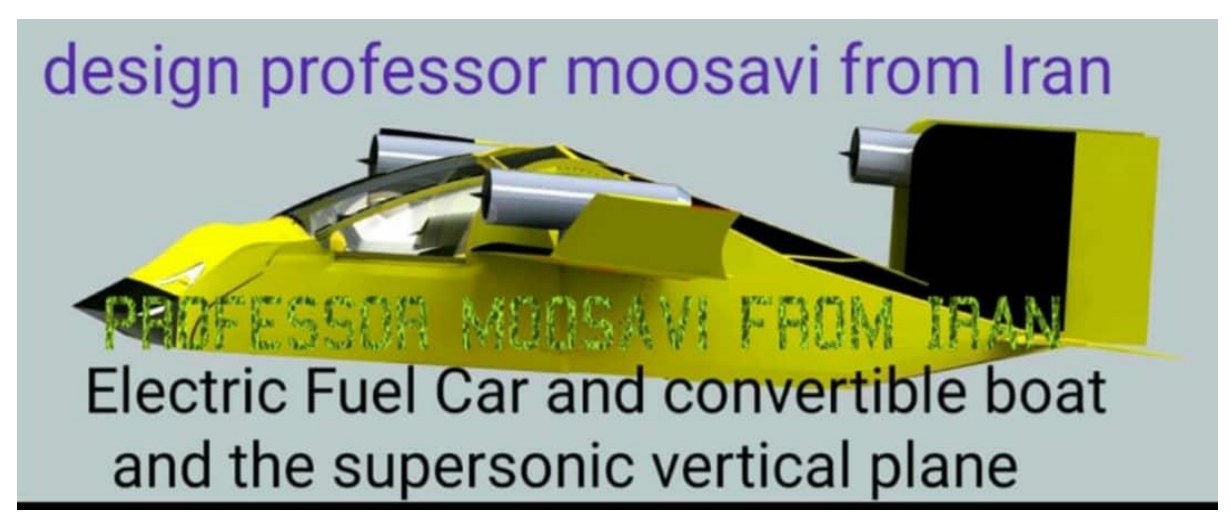

Fig. 2: In airplane mode

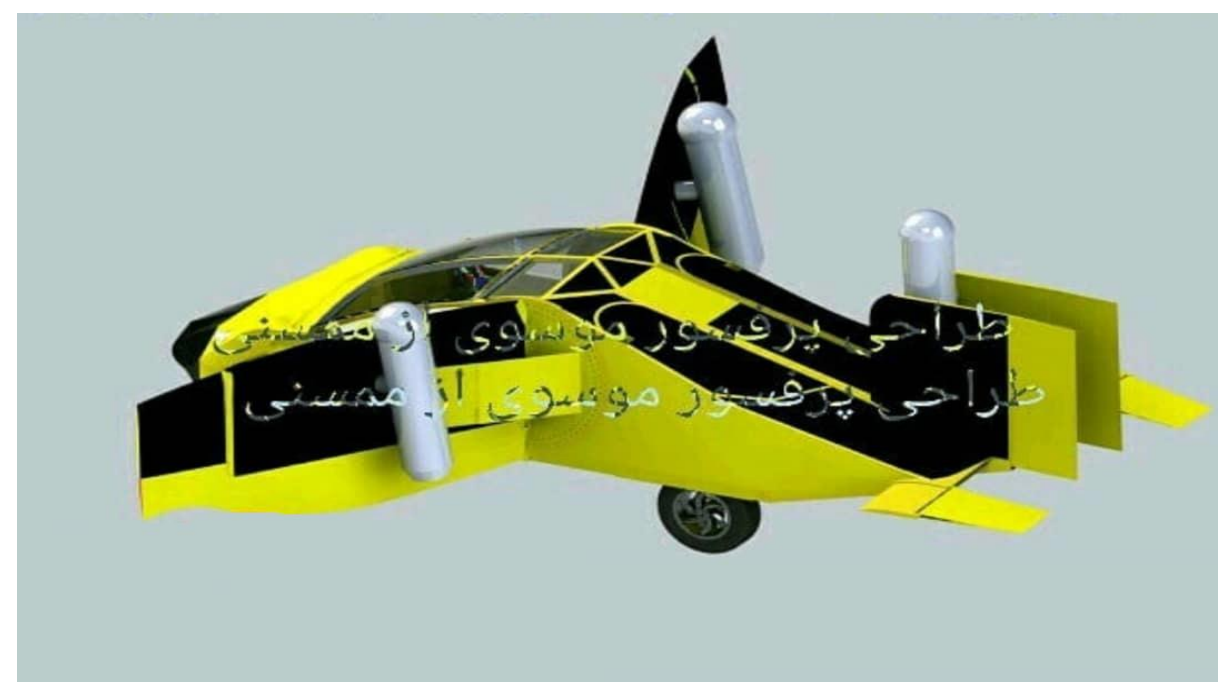

Fig. 3: In vertical flight mode

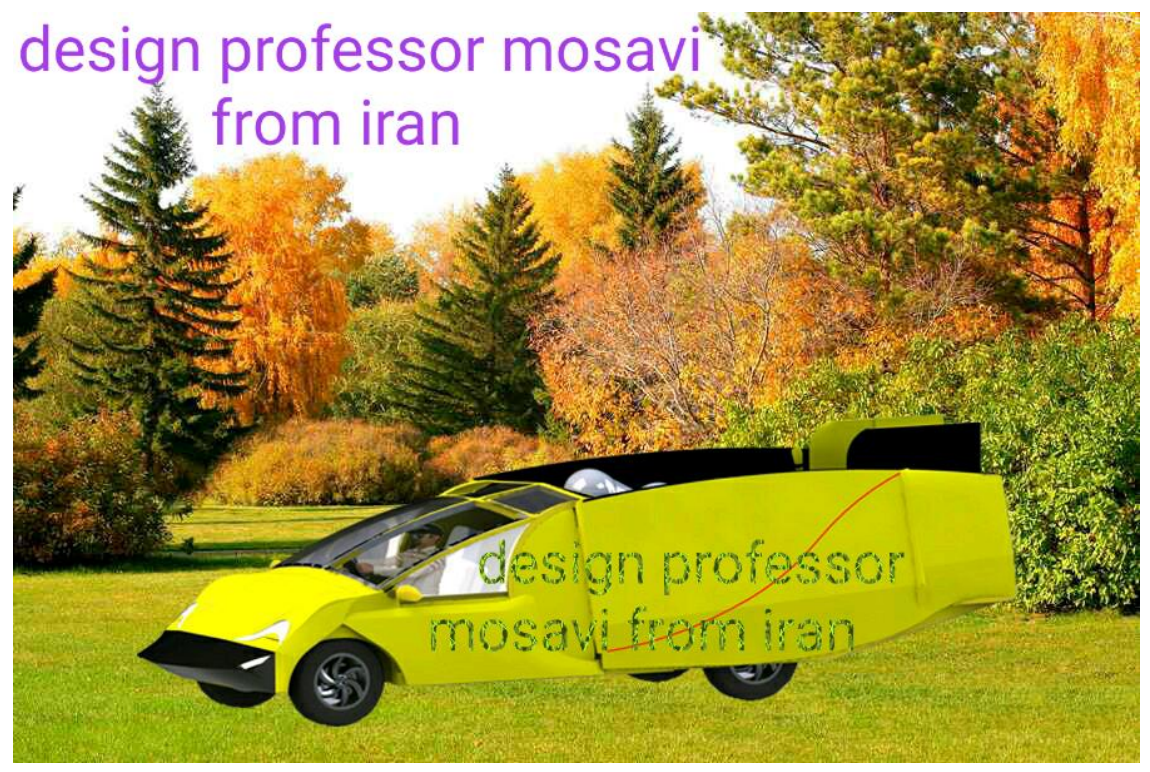

Fig. 4: In car mode 


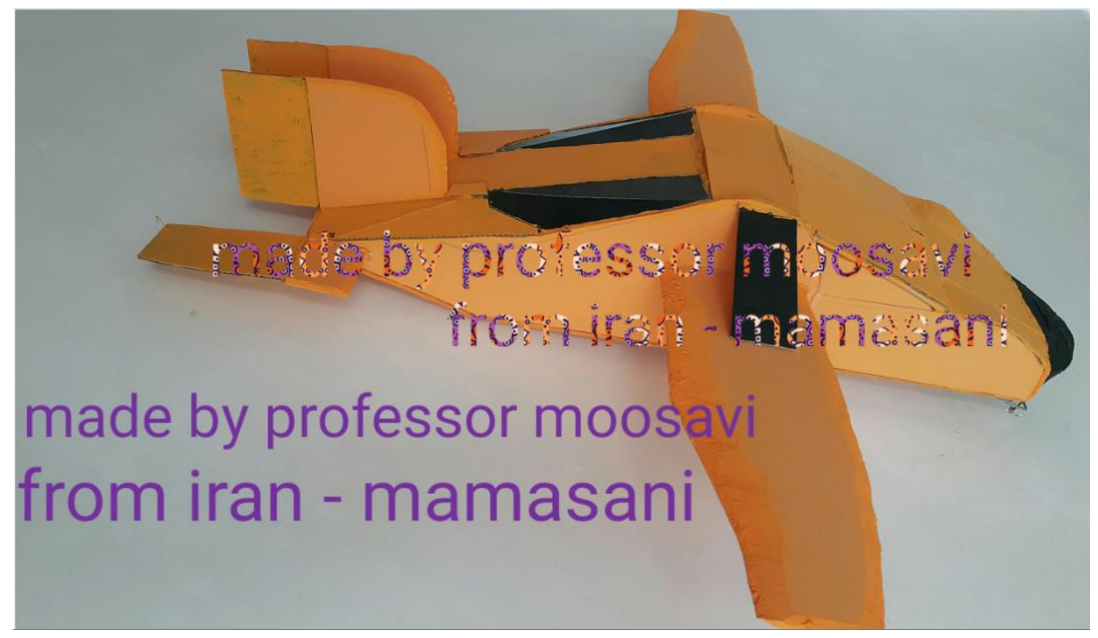

Fig. 5: Aerodynamic of plane model

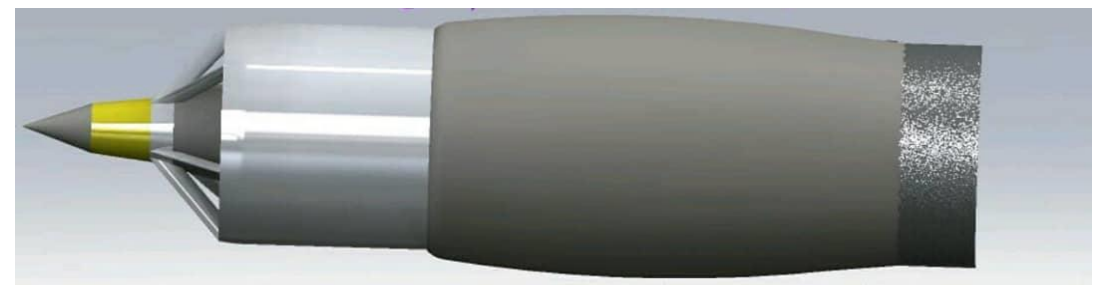

Fig. 6: Ramjet rocket turbo engines it is not complete yet

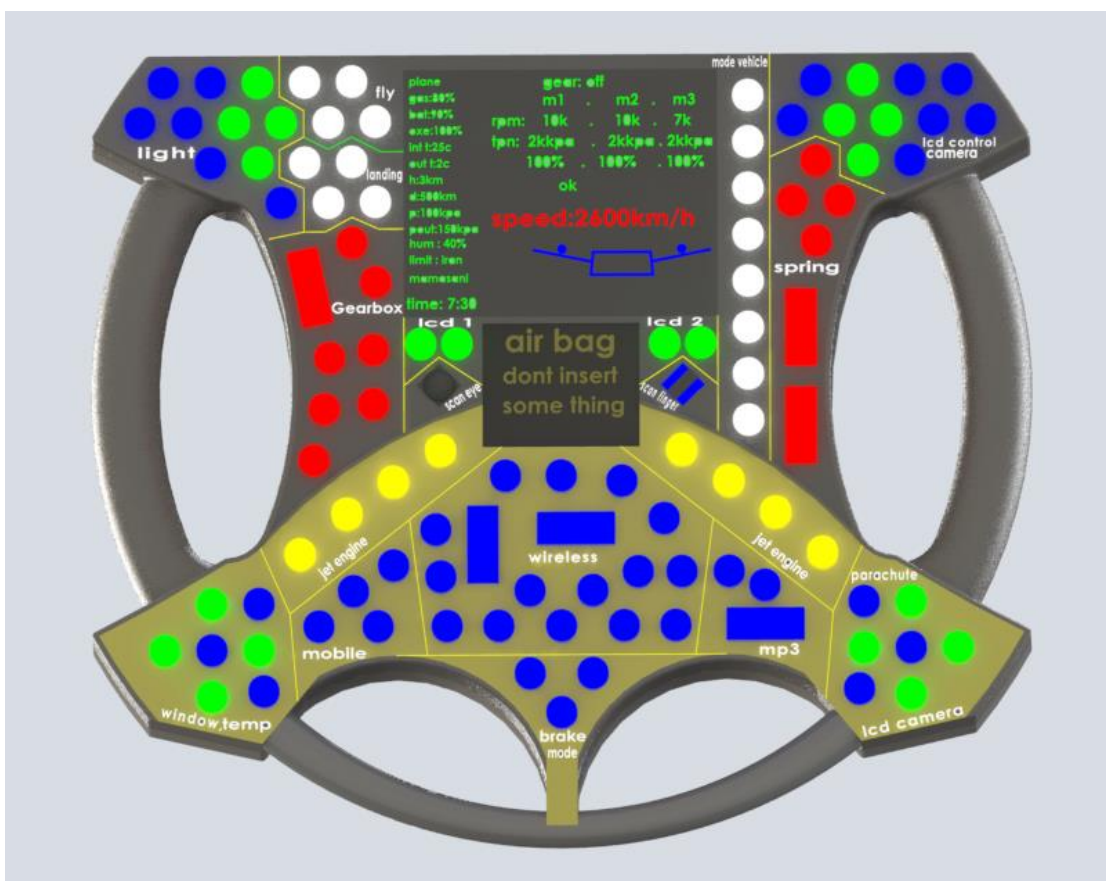

Fig. 7: Steering this vehicle

\section{System Anti-Abrasion Tire}

In this vehicle I have designed that tires rotate before landing till tires are not abrasion (is anti-abrasion).

\section{Specification of Shock Absorbers}

I designed these shock absorbers of several years of my experience conceptually and technologically on 
paper and it has the ability to absorb a free fall of $4 \mathrm{~m}$ on $1 \mathrm{~m}$ shock absorbers and maybe in testing, it can tolerate $7 \mathrm{~m}$ free fall in car mode (Fig. 4). These shock absorbers have a smart status and semi-smart of equilibrium and manual and it been designed from combining three shock absorbers:

a) The shock absorber produces electricity and has little oil that's not going to ruin and has a function of $20 \mathrm{~cm}$ in length

b) Electricity generator shock absorber and with low friction and long life and it is with a length function of $80 \mathrm{~cm}$ and it has the ability to be soft or stiff, smart, semi-smart and handy

c) Third shock absorber which is weak and low mass and it does the job of connecting the parts

\section{Batteries}

The number of batteries and their types are as follows:

a) Lithium Charge Batteries

It is Located at Floor of the car and the battery gives itself temperature to the aluminum body and battery number is less than the Tesla car battery and it gives the ability to move for $30 \mathrm{~min}$ at a speed of about 100 kilometers. Although low but the jet engine also has the power it needs

b) Solar Battery:

It's on the waist of the car and some on the wings

c) Thermal battery located on the jet engine exhaust and it has little efficiency. Might I do not install because it doesn't economic efficiency

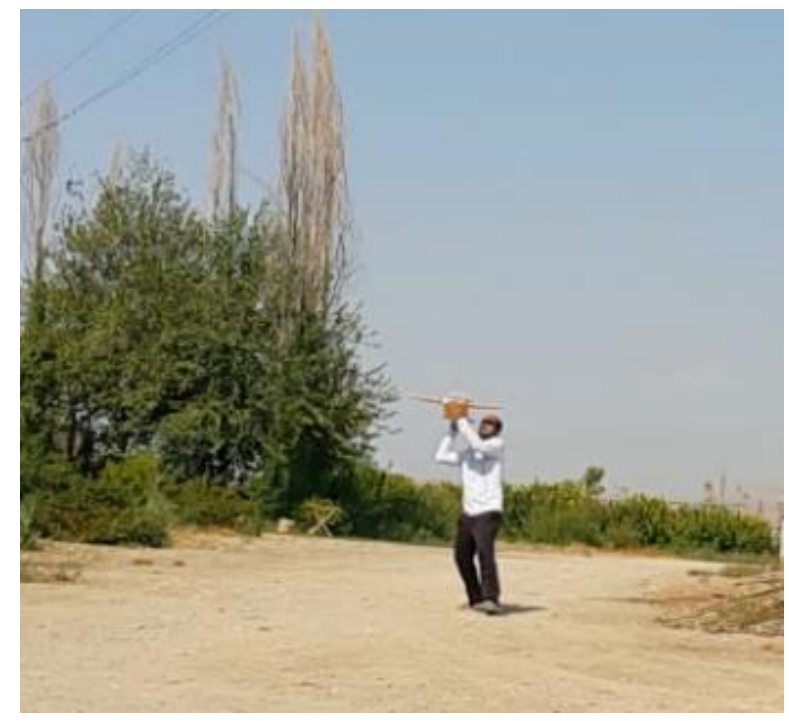

Fig. 8: Test of aerodynamic of plane model (The first photo)

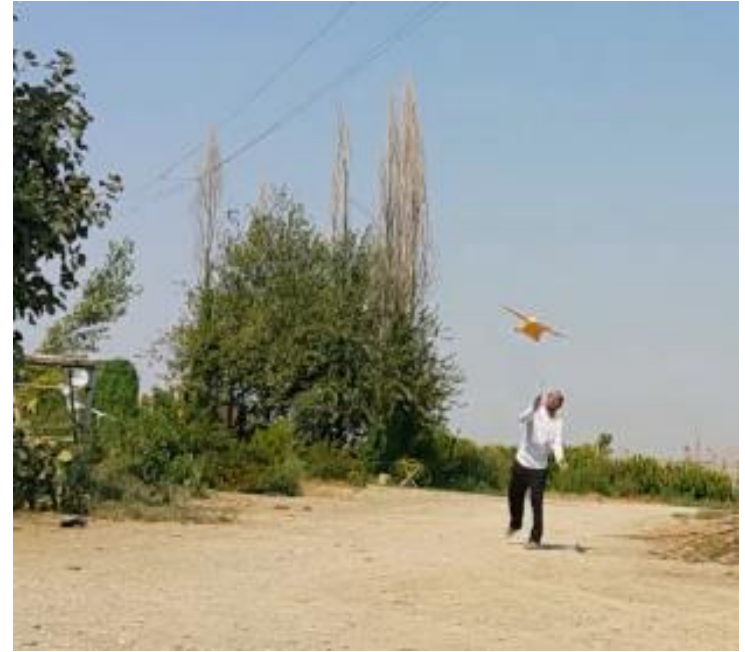

Fig. 9: Test of aerodynamic of plane model (The second photo)

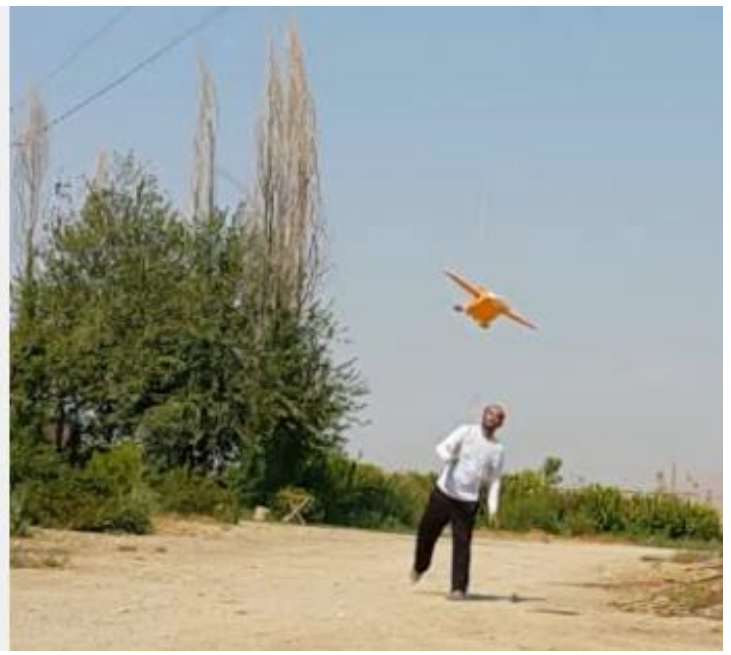

Fig. 10: Test of aerodynamic of plane model (the Third photo)

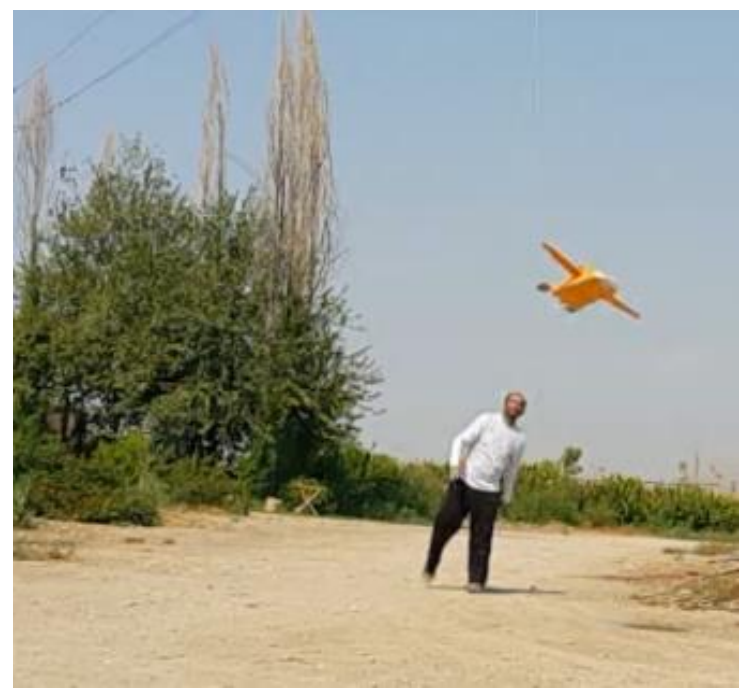

Fig. 11: Test of aerodynamic of plane model (the Fourth photo) 


\section{Results}

This vehicle includes 9 generations.

\section{Jet Engine Table (Table 1) ALMOST}

Table 1: Jet Engine Specification table, which I have to design and build

\begin{tabular}{lllll}
\hline Vehicle Mass & $\begin{array}{l}\text { Dimensions of } \\
\text { jet engine }\end{array}$ & $\begin{array}{l}\text { Number of ramjet rocket } \\
\text { turbo engines on this device }\end{array}$ & $\begin{array}{l}\text { The jet engine mass } \\
\text { necessary on the account of kg }\end{array}$ & $\begin{array}{l}\text { Max thrust in kg } \\
\text { (stand up mass) }\end{array}$ \\
\hline 1700 to $2300 \mathrm{~kg}$ & $\begin{array}{l}40 \mathrm{~cm} \text { in diameter } \\
\text { and } 140 \mathrm{~cm} \text { high }\end{array}$ & 3 Number & $100 \mathrm{~kg}$ & $\begin{array}{l}1000 \mathrm{~kg} \text { of turbo } \\
1300 \mathrm{~kg} \text { rocket }\end{array}$ \\
\hline
\end{tabular}

\section{Table 2 of this Vehicle}

Table 2: Vehicle weight and maximum cargo capacity and number of passengers

\begin{tabular}{lll}
\hline Mass $(\mathrm{kg})$ or the number of passengers & Vehicle mass $(\mathrm{kg})$ & Type of situation \\
\hline $1000 \mathrm{~kg}$ or 6 people & 1700 to $2300 \mathrm{~kg}$ & Military vehicle \\
$1000 \mathrm{~kg}$ or 5 people & 1700 to $2300 \mathrm{~kg}$ & Ambulance car \\
$500 \mathrm{~kg}$ or 5 people & 1700 to $2300 \mathrm{~kg}$ & Vertical flight aircraft \\
$700 \mathrm{~kg}$ or $5-6$ people & 1700 to $2300 \mathrm{~kg}$ & Horizontal flight aircraft \\
$1000 \mathrm{~kg}$ or 6 people & 1700 to $2300 \mathrm{~kg}$ & Motorboat \\
\hline
\end{tabular}

\section{Dimensions in all Modes}

Tire dimensions:

Diameter: $70 \mathrm{~cm}$; Tire width (cylindrical tire height): 17 $\mathrm{cm}$.

Dimensions in car mode:

Length: $6.3 \mathrm{~m}$; Width of $2 \mathrm{~m}$; Height without tire: 120 $140 \mathrm{~cm}$; Height with long chassis: 220-240 cm.

Dimensions in airplane and boat mode:

Dimensions of tip of two wings: 6 to $8 \mathrm{~m}$; Length: $6.8 \mathrm{~m}$.

\section{Maintenance Costs}

Since this car is small in size and has parachutes, the parachute can be opened and spread over the car in two layers and park in a small hangar measuring $4 * 8 \mathrm{~m}$ that occupies less space than a 5-passenger plane or a 5-passenger helicopter and it is very convenient for the aircraft navy carrier because it is very suitable for maritime military and political affairs because it has become a boat.

\section{Tests and Experiments}

The static tests of the important sections are analyzed but it's not perfect and the project will not fail and it's done in software too and no problem.

Dynamic testing of vehicle conversions has also been done in software but the design and behavioral analysis of the parts is not over yet.

Aerodynamic tests in software are not complete and accurate, for this reason I made a small sample of aerodynamics and I tested it with a small hand throwing test and he flew the $5 \mathrm{~m}$ route with balance and I've been successful (Fig. 8 to 11).

When this test is successful without equilibrium sensors, so no doubt I'll be quite successful with the balance sensors.

\section{Discussion}

I have designed the car in somehow that each piece does about 5 common and independent works with other pieces such as electric motor, generator, part of brake, clutch, gearbox and etc. Can be done by one piece too.

For this reason it has weighs half a similar aircraft. So there are no failures in mission.

\section{Mechanical and Mechatronic System Components}

(1) Jet Engines (2) Gearboxes and Transmission Systems (3) Clutch and Brake Systems (4) Differential (5) Wings (6) Tail (7) Skeleton (8) Body (9) Tires (10) Chamber (11) Bearings such as Ceramic Jet Engine Bearings etc., (12) Joints and Bearings (13) Suspension (14) Axle or Back (15) Eighth Steering System (16) Temperature, Heating, Cooling and Antifreeze and Barometer Control Systems (17) Wiperable wiper top compartment hood (18) Front door doors (19) Exhausts (20) Aircraft Hydraulic System (21)...

\section{Specifications of the Jet Engine Required for this Project}

The dimensions of this turbo rocket and ramjet engine I designed are about $40 \mathrm{~cm}$ in diameter and about $140 \mathrm{~cm}$ in height. 
For 20 years experiment on how to burn fuel I discovered a method that the co-produced gas (Co gas) was almost zero. If this method reaches the combustion chamber of the jet engine, pollution will be almost zero.

Because the jet engine has a lot of waste in the hydraulic, gearbox and pneumatic parts I have omitted these parts in technology design and replaced the electrical system there that are about 6 starters and 2 generator motors and 2 electric and 2 clutch motors and they replace each other in times of failure.

A new cooling system with very low controlled air cools the compressor and turbine without leak liquids and I have designed a new engine in which the main gearbox has been omitted and replaced it with a new and temporary. I have increased the engine's thrust to 1.5-2 and I have succeeded to combine the Ramjet engine to Turbo engine in the $10 \%$ scale design on paper, the Ramjet and I attached the rocket motor to this part as well. The flame temperature is also controlled in the combustion chamber and in the turbine till the Parts do not become fatigue, because the fuel explodes in the combustion chamber with compressed air(temperature more than necessary) or oxygen in complete combustion (burning a high percentage of saturated fuel in the air) and the flame temperature of the combustion reaches about $1200^{\circ} \mathrm{C}$ or more, but with my new cooling system design and the use of ceramic materials, there is no need to use Afterburner and increase waste.

\section{Afterburner}

Of course, the design of a flying car and boat with a simple turbo jet engine without Ramjet is capable of execution, so there is no problem in making the technology of this vehicle if the turbine blade of the motor is affected by fatigue phenomenon I have an idea that I have not explored yet that a particular system understands and sends data to the central circuit motor and the central computer and warns and work on low power before breaking the blades or motor turbine blade gathers and motor goes to rocket mode and prevent vertical crash and even less likely if the turbine blades suddenly break again motor can switch to rocket mode and in these conditions there is no chance of a crash but the system still can throw the parachute to air in a few milliseconds and it explodes in the air and it opens the parachute (Fig. 12).

\section{Wings}

For this project, I have designed the wing that with a marvelous mechanism, each wing is four pieces and it's folding (like birds) and puts it on the body. I designed this wing with a special electric jack and the wings open or close in about 2 to $8 \mathrm{sec}$.

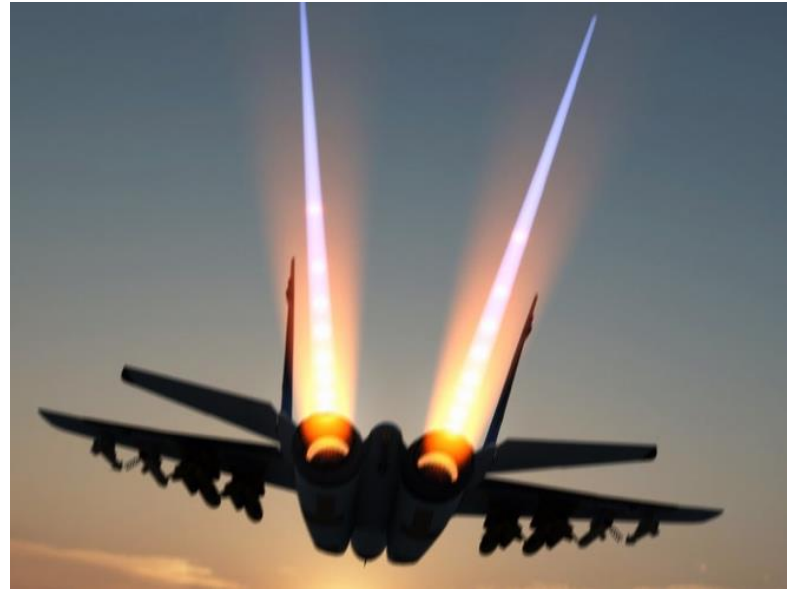

Fig. 12: Afterburner

\section{Electric Motors}

There are more than 46 big and small Gearboxes motor and without the Gearbox that is without abrasion that does all work the driving and oxygenation and parachute and there are about 12 numbers in each jet engine and does fuel work, conversion and electrical. The main engine system performs five other important tasks independently but jointly with other components (very advanced mechanism).

\section{Exhaust 2}

The mechanism used in this exhaust 2 in belly of flying car and it takes more energy from the jet engine and the exhaust noise of the jet engine is reduced to about $30 \%$, it transmits power to the transmission system jointly with two jet engines and two electric motors and transmits power from about 1,000 to 5,000 horsepower to lithium-electric battery and charging generators and wheels, that Transmits about $20 \%$ to the front and rear wheels (If more than 500 horsepower is applied to the wheels, there is a possibility of fatigue or breakage, so in design and experiment, mechanical analysis must be well done) and after a few minutes, the jet engines shut down and continue running with the electric system.

\section{Room Air Pressure Adjustment System}

The design is simple and it's not designed yet, two tubes from the compressor jet engines of two wings go into the room and smart valve returns to the compressor or exits from the back car room, or if this system crashes, the air comes out of some regulator valves in the back of the car room.

\section{Electronic and Electrical System Components}

1) 2 computers for automated flight and driving and boats 
2) Automatic microcontroller circuits for flying, driving and boats

3) Manage four acceleration sensors and gyroscope sensors and Gps sensors

4) Hall sensors, angle, optical, barometer, thermometer, Telemetry, torque gauge, speedometer, horizon meter, compass, Fatigue gauge (important), stress gauge (important), oxygen meter, Motor power meter, smoke meter (co2, co), range gauge, thrust gauges, Stall sensor and etc. (5) Radar (6) collision warning system with barrier With 5 types of lasers, infrared, sound (sonar), radar 7) Warm wind sensor ascending (8) Sensors sensing objects approaching like missiles (9) Oil and fuel barometer systems (10) Power supply and charging circuit (11) etc.

\section{Design Specifications of Conversion and Project Tests}

\section{Automotive}

Hybrid electric car and hybrid Ramjet Rocket Turbo engine with new cooling system of combustion chamber (Fig. 6).

\section{Ambulance and Potential Capabilities}

Ability to become a long and short chassis ambulance car and four-wheel drive (independent rear and front) and moving from rear to high speed up to 48 rear gears and 48 front gears and flawless movement of sideways and anti-collision using special shields called explosives is for many times that can endure crash with speed of 40 $\mathrm{km}$ or up to $80 \mathrm{~km}$ with a wall with no damage. It has 7 types of brakes that if all of these brakes are active before the accident it can stop the car at speeds of 200 kilometers in $2 \mathrm{sec}$ or maybe even less but it can use about 4-5 brakes simultaneously and the other are in common with tire brake (Brake to the tire):

1) Electric discs to the tires

2) Electric motor to the tires

3) Towing wire to discs and tires

4) Jet engine to the tire (turbo rocket)

5) Clutch to the tire

6) Aerodynamics, increasing the level of air contact (drag phenomenon)

7) Jet engine to front the air in mode of car

8) Parachute

\section{Vertical Flight Capability}

It consumes a lot of fuel. The car can be transformed into a jet aircraft by removing wings and engines from the body and power transmission system.

There are 3 turbo jet engines running at the same time and three rocket engines are reserved within the other three engines that can replace three motors.
If turbo break down, it is turn on rocket motor by blowing oxygen in a few milliseconds and the other three ramjet engines are not active because it is activated at near-sound speed, in this case, the plane will increase to $2 \mathrm{~m}$ in length with a mechanism and it has potential power and it has maneuverability in 12 directions:

Direction (right, left, front and back) and tilt (right, left, front and back) and height (increase and decrease) and rotation (right and left) all of these movements are controlled easily (by a computer or electronic circuit or a pilot's steering).

\section{Supersonic Horizontal Flight Plane}

In this state, the 3 shock absorbers and tires are folded into the fender with a special mechanism and compressed. I have succeeded in designing $1 \%$ volume scale on paper and another application motor closes the gate (multi-purpose common gearbox) and it is anti-leakage. The fins and shields and the direction of the engine force change little by little and it becomes to supersonic turbo rocket plane that it was designed conceptually on paper in 2005 and at high speeds. In more than $700 \mathrm{~km}$ of turbo engines are turned off and the rocket engine will be turned off by oxygen for 30 to $60 \mathrm{sec}$ and at high altitude. Gradually, with the change in engines (unlike the turbocharged sr71 engine), the rocket engine turns to the ramjet and reaches to speed supersonic of 1500 $\mathrm{km}$ that I succeeded in designing technology on paper with a scale volumetric of $1 \%$ in 2019 .

\section{In Motor Boat Mode}

For the ability to land on sea or river water requires landing in airplane or semi-aircraft mode and it is necessary to collect the shock absorber and the tire inside the car fender and with changes in jet engines, wing, shields and under-wing parts, it can land on water mode that brushless motors and stepper motors and electric and electronic system and mechanical system are waterproof and the thrust is supplied by a rocket engine or turbojet (Fig. 2).

\section{Expert of Similar Projects}

Compare similar projects with my project:

\section{Vertical Flight Aircraft f35}

Since this aircraft only has a turbojet engine, chances are that this engine will malfunction and there is the plane crash and it can't be a small car and it doesn't have rocket and ramjet engines and because of that, it has less flight radius and compared to my project, it has not just the left and right directions but it does so by changing the slope and the exhaust $\mathrm{f} 35$ is a broken knee in perpendicular flight mode and it doesn't have very good 
vertical flight performance that my project does not have these problems (Fig. 3).

\section{Rescue Helicopter}

This device is capable of landing and flying vertically and has a speed of about $300 \mathrm{~km}$ and it can be waterproof and land on the sea but it has likely to crash and there is no parachute and it can't land or move in the forest so it's very dangerous.

I didn't find the advantages Helicopter of Rescue than attribution to my project.

\section{Rescue Plane}

Can't fly vertically and not suitable for mountainous areas but it can operate on sea or river and it's too big. I didn't find the advantages Plane of Rescue than attribution to my project.

\section{Vertical Aircraft Like v22}

It is a combination of helicopters and aircraft but it's big and it's not supersonic.

\section{Ambulance Car}

Ambulance car is capable of carrying relief operations only in the city and it's cheap and there is a chance of an accident.

\section{Rescue Motor Boat}

This relief device can only help at sea. These types of boats do not sink easily and have a speed of about 100 kilometers and they can't get the patient to the hospital so time is not enough. I didn't find the advantages Rescue Motor Boat than attribution to my project.

\section{Anti-Crash and Anti-Accident Systems}

\section{Has 6 Jet Turbo Rocket Engines}

If without service, one of the turbojet engines will fail, nothing happens and it goes rocket mode and if the engines are made with high quality parts, with a probability of about 0.001 a full engine (turbo rocket) during example $1000 \mathrm{~h}$ of vertical flight may be disabled and the parachute must be launched to air and blown up delay 10 milliseconds and it open but it does not fall free in the supersonic aircraft mode because the parachute is be torn but $1,000 \mathrm{~h}$ of vertical flight equals about 10,000 $\mathrm{h}$ of both vertical and horizontal flight that's remarkable and marvelous.

\section{In Mode of Supersonic}

In this case, the aerodynamic side brakes and explosive shields operate with the pressure of the air tank and with the use of powerful motor of shock absorber, the tires open and speed of supersonic aircraft is to low and parachute is open and it is stops the crash.
If engines and systems are serviced continuously and periodically, you never need to use a parachute it will only be used for hangar.

In plane mode, if the plane is not serviced and a complete engine (turbo rocket) shut down it can still go its own way and if two Turbo Rocket engines fail, it can land horizontally at a speed of $200 \mathrm{~km}$ on a street or airport and stop using your brakes quickly and reach the destination.

In landscape mode, if the car is not serviced and a complete engine (turbocharged rocket launcher) shut down it can still go its own way and if two Turbo Rocket engines fail, it can landing horizontally at a speed of 200 $\mathrm{km}$ on a street or airport and stop with brakes quickly and reach the destination.

If at the same time 6 engines fail that is very, very unlikely, Horizontal falls occur but again, the explosive aerodynamic brakes and explosive shields and parachute prevent the crash from falling even at supersonic speeds and with the help of 1-meter shock absorbers and tires, it can sit on the ground.

\section{Independent Systems and Working Together}

Most systems in this vehicle have a combination of three or four anti-crash.

Electronic systems and engines and the wing angle and wings movable blade Perform anti-fall control operations.

These systems are independent in most of their parts and they are related in a small part.

\section{Tail and Wing}

The vertical tail of the aircraft can do the front wing work with together. The front wing has 6 independent systems and works together and performs vehicle conversion. In this system, the phenomenon of aircraft Stall has no effect, unless the pilot orders the brake.

\section{Horizontal Tail and Rear Jet Engine}

Two horizontal tails of the aircraft and the rear jet engine and small wings vertical tail can do the job of ascending and descending the plane and if all three systems fail together that is very little, to be around 0.001 . It crashes. That again too, air brake systems and aerodynamics and parachute and tires with the help of a one-meter shock absorber springs, prevents crash.

\section{Technical Anti-Breakdown Systems}

The vehicle uses high-quality, anti-burn electronic systems (Such as removing relays and removing some electronic components and removing some electrical components) and many parts are used commonly and at low cost, like several starter motors and 6 jet engines and two electric motors and there are two powerful starter engines I have called it a shared driving force. 
Of course, jet engines and the fins prevent accidents and deflection at high speeds (about 300 $\mathrm{km} / \mathrm{h}$ ) in the car plane, mode on road (open winged compressed plane) and that the 5 brakes also prevent accident.

\section{Equipment Management System Algorithm}

I invented this algorithm several years ago, now I'm reviewing electronic systems and programming and will be tested on the vehicle's computer and advanced microcontrollers and parts of the vehicle and I will send in vehicle other articles in Publication.

\section{Radio and Communication System}

Another system is used in this project, if communication systems fail, it warns both to watchtower and other planes.

\section{Fire-Fighting System}

A fire extinguisher can be installed for this car and the car's fuel tanks are equipped with a special invention technology of automatic Fire-fighting that I myself have designed.

\section{The Next Generations of this Vehicle}

By doing more experiments and better design,

I want to design this vehicle very aerodynamically in the next generations and it reach hypersonic speeds $(7000 \mathrm{~km} / \mathrm{h})$, but it has no ambulance application.

The next generations of this vehicle have the ability to operate in the snow.

And in some of these generations, fuel and electric motors have retractable propellers.

In some generations of this vehicle, the disc brakes are removed and special electric brakes will replace the disc brake.

\section{Conclusion}

We conclude from these discussions that this car boat vertical flying supersonic and is anti-accident and it is very good for faraway items (at least $30 \mathrm{~km}$ ) or emergency near $(\max .30 \mathrm{~km})$ that it is suitable for the United Nations and international organizations such as the International Red Cross. It also use for security, judicial, service, military.

\section{Acknowledgment}

I am a professor and inventor and I had my lab and workshop and I have. I am proficient in most sciences and technology and I didn't have financial support and I can make tools out of soil and recycled materials.

\section{Funding Information}

Budget for making this vehicle:

1) Metallurgical machines (powder, casting, etc.)

2) Sheet and tube laser cutting machines

3) Welding tools for steel, iron, aluminum and ... like Welding electricity, argon, plasma and etc. Carbon Fiber Composite Machines

4) Maybe I can master the technology of ceramics myself but contact with a ceramic manufacturing company or a low-level ceramic manufacturing line is required and is may be necessary to Recruitment a specialist and a ceramic worker in the destination country

5) Designing devices

And manufacturing of multilayer polymer electronics circuits and ceramic and microcontrollers

6) Multiple computer devices.

7) Mechanical devices such as sheet bending and wiring work, large and mini lathing, cnc and ordinary $3 \mathrm{D}$ printer and industrial, wind tunnel and mechanical testing devices (tension, strain, pressure, ...)

8) Polymer parts making machines like polymer injection

And etc.

\section{Conflict of Interest}

Automotive companies, aircraft companies and manufacturing companies are affected.

\section{References}

The information in the text is my own research information and test in my lab and my workroom and it's accurate. 